\title{
The role of the clinical nurse specialist in caring for patients with prostate cancer: a narrative review
}

This article was published in the following Dove Press journal:

Nursing: Research and Reviews

18 July 2014

Number of times this article has been viewed

\author{
Maria Helena Baena de \\ Moraes Lopes' \\ Rosângela Higa ${ }^{2}$ \\ 'Faculty of Nursing, University of \\ Campinas, Campinas, São Paulo, \\ Brazil; ${ }^{2}$ Nursing Department, \\ Prof Dr José Aristodemo Pinotti \\ Women's Hospital, CAISM, University \\ of Campinas, Campinas, São Paulo, \\ Brazil
}

\begin{abstract}
Prostate cancer, the leading cancer among men, constitutes a serious public health problem worldwide. Its treatment and care require a multi-professional approach. This descriptive review was conducted to establish the role of the clinical nurse specialist in providing prostate cancer care. The CINAHL, MEDLINE, PubMed, Medscape, LILACS, BDENF, and Cochrane databases were searched to identify relevant publications up to September 2013 written in Portuguese, English, and Spanish, using the Electronic Information Access Program and Coordination for the Improvement of Higher Education Personnel (CAPES) Periodicals Portal in the search system of the Digital Library of the University of Campinas, São Paulo, Brazil. Articles not present in these databases or that did not discuss nursing care for men with prostate cancer and/or their families were excluded. Analysis of 20 studies selected according to these criteria revealed four important aspects of specialized nursing care: care provided 1) at the time of prostate cancer diagnosis; in the 2) pretreatment and 3) posttreatment periods; and 4) in the assistance of partners and family members of men with prostate cancer. The studies included in the analysis showed that physical and psychological problems, such as loss of energy and motivation, functional impairment, and loss of sex life, were relevant to nursing care. They confirmed that nursing care actions for men with prostate cancer should start at the time of diagnosis, when patients must participate in deciding the best course of treatment. During the prostatectomy period, care involves preoperative preparation, which is fundamental for recovery and adaption to postoperative sequelae. Family members, especially partners, should also receive attention and support during this period. The results allowed the conclusion that the role of the clinical nurse specialist in the care of men with prostate cancer is broad and essential, but interventions and new strategies of care need to be evaluated through well-designed clinical studies.
\end{abstract}

Keywords: prostatic neoplasm, nursing care, nurse clinician, prostatectomy, review literature as topic

\section{Introduction}

Prostate cancer $(\mathrm{PCa})$ constitutes a serious public health problem worldwide. It is the fourth most common cancer and the second most common cancer in men. An estimated 1.1 million men worldwide were diagnosed with PCa in 2012, accounting for $15 \%$ of cancers diagnosed in men, with almost $70 \%(759,000)$ of cases occurring in more developed regions. ${ }^{1}$ The rates are highest in Australia/New Zealand and North America, with age-standardized rates of 111.6 and 97.2 per 100,000, respectively, and in Western and Northern Europe, due to the practice of prostate-specific antigen (PSA) testing and subsequent biopsy in these regions. Incidence rates are also relatively high in the Caribbean (79.8 per 100,000), Southern Africa (61.8 per 100,000), and South America (60.1 per 100,000), whereas they are low in Asian populations
Correspondence: Maria Helena Baena de Moraes Lopes

Faculty of Nursing, University of

Campinas, I26 Rua Tessália Vieira de

Camargo, Campinas, São Paulo,

Brazil, CEP |3084-97|

$\mathrm{Tel}+55$ I9 352। 883।

Fax +55 I9 352। 8822

Email mhbaena@fcm.unicamp.br;

mhbaenaml@yahoo.com.br 
(10.5 per 100,000), particularly in eastern and south-central Asia (4.5 per 100,000). ${ }^{1} \mathrm{PCa}$ is the fifth leading cause of death from cancer in men $(6.6 \%$ of all deaths), with an estimated 307,000 deaths occurring due to this disease in 2012 . $^{1}$

The incidence of PCa is high, but the rate of mortality due to this cancer is much lower. Furthermore, the incidence of small, localized, well-differentiated PCa is increasing as a result of PSA screening and prostate biopsy. Many men with localized PCa would not benefit from definitive treatment; rather, two conservative management strategies can be used in this subgroup of patients: "watchful waiting" and "active surveillance". 2

Watchful waiting is also known as "deferred" or "symptom-guided" treatment. This term was first used before 1990 (pre-PSA screening era) to refer to the conservative management of PCa until the development of local or systemic progression. Then, the patient would receive palliative treatment for urinary tract obstruction (eg, transurethral resection of the prostate) and metastatic lesions (hormonal therapy or radiotherapy). ${ }^{2}$

Active surveillance or "active monitoring" is a term for the conservative management of PCa introduced in the past decade. It involves the active decision to not treat the patient immediately. Rather, the patient is followed closely and treated at predefined thresholds representing progression (ie, short PSA doubling time and deteriorating histopathological factors on repeat biopsy); treatment is intended to be curative. $^{2}$

The surgical treatment of PCa consists of radical prostatectomy (RP), which involves removal of the entire prostate gland and resection of both seminal vesicles with sufficient surrounding tissue to obtain a negative margin. This procedure is often accompanied by bilateral pelvic lymph-node dissection. ${ }^{2}$ However, urinary incontinence (UI) and sexual impotence are serious complications of RP that significantly compromise patients' quality of life. ${ }^{3}$ Other complications are intraoperative bleeding and bladder neck stricture. ${ }^{4}$ A 2012 integrative review classified nursing care following prostatectomy using six categories: psychological follow-up; orientation in the preoperative period; and the treatments of erectile dysfunction, UI, pain, and hyponatremia. ${ }^{5}$

Radiotherapy is an alternative to surgery, and the gold standard for external-beam radiotherapy is intensitymodulated radiotherapy with or without image guidance. Besides external irradiation, transperineal low-dose- or high-dose-rate brachytherapy may be used. ${ }^{2}$ Prostate external-beam radiotherapy has acute and late side effects, such as diarrhea, cystitis, fatigue, mild skin irritation, and erectile dysfunction. Complications of brachytherapy include pain, cystitis symptoms, hematuria, infection, enteritis, and fatigue. Several nursing interventions, including the provision of instructions to patients and families, are required for the management of these problems. ${ }^{6}$

Prostate cells depend on androgens to stimulate growth, function, and proliferation. Androgen-suppressing strategies have been used in the management of advanced PCa; these strategies involve the suppression of testicular androgen secretion by surgical or medical castration and/or inhibition of the action of circulating androgens at the receptor level in prostate cells using competing compounds (antiandrogens). These two methods can be combined to achieve complete androgen blockade. ${ }^{2}$

Some men consider orchiectomy to be an unacceptable assault on their manhood, and this form of treatment may have a negative psychological effect. ${ }^{2}$ Treatment with steroidal antiandrogens may have pharmacological side effects, such as loss of libido, erectile dysfunction, and, rarely, gynecomastia; and nonpharmacological side effects, such as cardiovascular toxicity and hepatotoxicity. ${ }^{2}$ Thus, nursing care for men with advanced PCa must consider these side effects and their physical and psychological impacts. In general, the key nursing tasks include the provision of: support at the time of initial diagnosis; individualized information; support with treatment decision making; advice on the management of symptoms and side effects; support and assistance with practical issues, such as finances and obtaining benefits and/or home assistance; emotional and psychological support; reference to specialized services and support services; and readily available contact for the patient. ${ }^{7}$

$\mathrm{PCa}$ and the complications of its treatment do not affect men with this disease alone; their partners suffer psychological distress, fatigue, and changes in and limitations on social and sexual life. ${ }^{8}$ A longitudinal survey evaluating the health status, health-related quality of life, and marital satisfaction of couples dealing with PCa from the pretreatment period to 18 months after treatment demonstrated that patients and their partners are affected by the PCa treatment experience. ${ }^{9}$ Thus, nursing care must include not only men with PCa, but also their partners and family members. This complex task requires expertise.

Clinical nurse specialists have in-depth knowledge of the physical, psychological, and social effects of $\mathrm{PCa}$ and play a key role in patient care. ${ }^{7}$ The International Council of Nurses (ICN) highlighted the demonstrated safety, effectiveness, and patient acceptance of advanced nursing roles, but also noted that definitions of a clinical nurse specialist vary 
among countries. ${ }^{10}$ To facilitate global understanding, the ICN defined a nurse practitioner/advanced practice nurse as:

a registered nurse who has acquired the expert knowledge base, complex decision-making skills and clinical competencies for expanded practice, the characteristics of which are shaped by the context and/or country in which s/he is credentialed to practice. $^{10}$

Considering all of these aspects related to $\mathrm{PCa}$, we conducted a narrative review to establish the role of the clinical nurse specialist in treating and managing this disease, from the time of diagnosis through the post-discharge period, including experiences from different countries.

\section{Methods}

Narrative reviews describe and discuss the state of science of a specific topic or theme. ${ }^{11}$ Thus, our purpose in this article is to present an overview of the role of the clinical nurse specialist in the care of men with PCa and their families. The following questions guided the study: What nursing practices are recommended for men with PCa from the time of diagnosis? How should partners and family members be involved in this process? Which approaches seem to achieve the best results?

The data sources were peer-reviewed journal articles, including reports of research and review articles, written in Portuguese, English, or Spanish, that described nursing care for men with $\mathrm{PCa}$ and/or their families, with no time limit. Considering that patients with $\mathrm{PCa}$ require complex care and that definitions of a clinical nurse specialist vary among countries, articles that described nursing interventions were included, independent of whether the authors mentioned these interventions in relation to the role of the clinical nurse. Books, theses, presentations at scientific meetings, editorials, letters to the editor, essays, and articles not included in the databases used for this study were excluded.

Between August 22 and September 14, 2013, a bibliographic search of the CINAHL, MEDLINE, PubMed, Medscape, LILACS, BDENF, and Cochrane databases was performed using the Electronic Information Access Program and the Capes Periodicals Portal in the search system of the Digital Library of the University of Campinas, São Paulo State, Brazil to identify publications up to September 2013. The following combinations of keywords with the Boolean operator "AND" were used: "prostate" AND “cancer" AND "clinical" AND "nursing" AND "care"; "prostate" AND "cancer" AND "nursing" AND "care"; "prostatectomy" AND "nursing" AND "care"; and "prostate cancer" AND "care" AND "clinical nurse".
Article selection involved the review of titles, then abstracts, and, finally, full texts. The full texts of the selected studies were read and the nursing care was categorized according to the article content and the questions that guided the study, with the aim of identifying physical, social, and psychological problems, as well as procedures that should be implemented from the time of PCa diagnosis through the posttreatment and rehabilitation periods.

\section{Results}

Table 1 shows the numbers of articles identified according to keyword combination and database, as well as the numbers selected according to title, abstract, and full text reviews. The majority of studies appeared in two or more databases. Articles were excluded mainly on the basis of title (indicating that the target was not the object of study); language

Table I Number of articles selected by title, abstract, and full text according to keywords and database

\begin{tabular}{|c|c|c|c|c|}
\hline \multirow[t]{2}{*}{ Database } & \multirow{2}{*}{$\begin{array}{l}\text { Total } \\
\text { identified, } \mathbf{n}\end{array}$} & \multicolumn{3}{|c|}{ Total selected, $\mathbf{n}$} \\
\hline & & Title & Abstract & Full text \\
\hline \multicolumn{5}{|c|}{ Keywords: "prostatectomy" AND "nursing" AND “care" } \\
\hline CINAHL & 3 & 3 & 2 & 1 \\
\hline Cochrane & 6 & 3 & 2 & 2 \\
\hline PubMed & 55 & 22 & 13 & 10 \\
\hline MEDLINE & 48 & 10 & 8 & 7 \\
\hline LILACS & 13 & 8 & 5 & 3 \\
\hline BDENF & 5 & 5 & 4 & 4 \\
\hline Total & 130 & 51 & 34 & 27 \\
\hline \multicolumn{5}{|c|}{ Keywords: "prostate" AND “cancer" AND "nursing” AND “care" } \\
\hline CINAHL & II & II & 5 & 5 \\
\hline Cochrane & 117 & I & 0 & 0 \\
\hline PubMed & 364 & 15 & 7 & 7 \\
\hline MEDLINE & 644 & 10 & 4 & 4 \\
\hline LILACS & 7 & 2 & 0 & 0 \\
\hline BDENF & 2 & I & 0 & 0 \\
\hline Total & 1,145 & 40 & 16 & 16 \\
\hline \multicolumn{5}{|c|}{ Keywords: "prostate" AND "cancer" AND "clinical” AND "nursing" } \\
\hline \multicolumn{5}{|c|}{ AND "care" } \\
\hline CINAHL & 0 & 0 & 0 & 0 \\
\hline Cochrane & 102 & 1 & 0 & 0 \\
\hline PubMed & 103 & 24 & 10 & 6 \\
\hline MEDLINE & 154 & 11 & 7 & 7 \\
\hline LILACS & 0 & 0 & 0 & 0 \\
\hline BDENF & 0 & 0 & 0 & 0 \\
\hline Total & 359 & 36 & 17 & 13 \\
\hline \multicolumn{5}{|c|}{ Keywords: "prostate cancer" AND "care" AND "clinical nurse" } \\
\hline CINAHL & 0 & 0 & 0 & 0 \\
\hline Cochrane & 64 & 2 & 1 & 1 \\
\hline PubMed & 25 & 7 & 6 & 6 \\
\hline MEDLINE & 21 & 10 & 4 & 4 \\
\hline LILACS & 0 & 0 & 0 & 0 \\
\hline BDENF & 0 & 0 & 0 & 0 \\
\hline Total & 110 & 19 & 11 & 11 \\
\hline
\end{tabular}


(eg, Japanese, Chinese); electronic unavailability of abstract and/or full text; publication of abstract in conference proceedings; and publication type (ie, thesis or guidelines).

Following data evaluation, the sample comprised 20 articles included in the CINAHL $(n=4), \operatorname{MEDLINE}(n=10)$, PubMed ( $n=13)$, LILACS ( $n=3), \operatorname{BDENF}(n=4)$, and Cochrane $(n=2)$ databases. Six studies appeared in a single database, 12 appeared in two, and two appeared in three databases. All articles appearing in the MEDLINE and Cochrane databases were also included in the PubMed database. The studies were published between 1997 and 2013, and were conducted in eight countries: the United States ( $n=7)$, Brazil $(n=4)$, United Kingdom ( $n=3)$, Canada ( $n=2)$, Finland $(n=1)$, Portugal $(n=1)$, Australia $(n=1)$, and Sweden $(n=1)$.

Table 2 presents a synthesis of the findings of analysis. The studies included in the analysis showed that physical and psychological problems, such as loss of energy and motivation, functional impairment, and loss of sex life, were relevant to nursing care. ${ }^{12}$ They confirmed that nursing care actions for men with PCa should start at the time of diagnosis, when patients must participate in deciding the best course of treatment. During the prostatectomy period, care involves preoperative preparation, which is fundamental for recovery and adaption to postoperative sequelae. ${ }^{13}$ Family members, especially partners, should also receive attention and support during this period. The analysis identified four important aspects of specialized nursing care: care provided 1) at the time of PCa diagnosis; 2) during the pretreatment period and 3 ) postoperatively; and 4) the provision of assistance to partners and family members of men with PCa.

\section{Nursing care at the time of PCa diagnosis}

Men with PCa have described physical and emotional difficulties around the time of diagnosis. ${ }^{14}$ Thus, nurses must encourage these patients to describe their experiences with diagnosis and the illness to facilitate their understanding of PCa. Nurses should provide accurate, complete, and consistent information to help patients understand the full implications of the disease process. ${ }^{15,16}$ Several studies reported that many men do not understand the information provided about PCa, its diagnosis, or treatment, including side effects such as urinary dysfunction, fatigue, and sexual issues. The lack of information about their diagnosis, available treatments, and prognosis causes patients to feel anger, frustration, fear, and uncertainty. ${ }^{14,17}$

In these cases, nurses can individualize patient care using an approach based on the experiences and understanding of men with PCa ${ }^{16}$ Clinical nurse specialists are very important in providing this kind of assistance because they help patients understand and come to terms with their diagnosis and treatment by presenting medical information in an understandable manner. This process involves patient-centered communication and the use of nonmedical language. ${ }^{18}$

In the diagnosis period, nurses must encourage men with PCa to participate in making the best treatment decisions, and support their families to enable them to face this problem without emotional distress. ${ }^{15}$ Patients assisted by specialist nurses are more likely to state that they selected the type of treatment, and that nurses provided the opportunity to talk about and reflect on the diagnosis, as well as providing information, support, and assistance with self-care. ${ }^{18}$

Clinical nurse specialists in urology are the ideal health professionals to help patients and their families through education, support, encouragement, and active listening. ${ }^{15}$ Nursing interventions must address the aspects most important to each patient, including helping him to understand $\mathrm{PCa}$; the benefits, risks, and potential side effects of available treatment options; and ways to cope with side effects. ${ }^{14,15,19}$

After treatment selection, these patients require careful follow-up to ensure the improvement of their knowledge and ability to cope with difficulties that may adversely influence treatment decisions and self-image, such as low socioeconomic status (eg, limited medical insurance, language difficulties, homelessness, cultural attitudes and beliefs); ${ }^{19}$ impotence and UI (common side effects of prostatectomy); feminization and loss of libido (after hormone therapy); and bowel disturbance (after internaland external-beam radiotherapy). ${ }^{20}$ Besides providing information about the disease and treatment offered and helping patients and family members cope with the illness throughout its trajectory, nurses should help patients manage symptoms and side effects and implement self-care measures. ${ }^{6}$ In addition to the management of self-care, the support provided by a health specialist team should include guidance in pre- and postoperative pelvic floor exercises and diets to manage the bowel effects of radiotherapy, penile rehabilitation for erectile dysfunction, and instruction in exercise programs to address fatigue caused by hormone therapy. ${ }^{20}$

\section{Nursing care in the pretreatment period}

During the preoperative period, when patients must come to terms with the indication for prostatectomy, nurses should encourage them to express their feelings and allow an 
exchange of information facilitating the planning of a highquality nursing intervention. ${ }^{21,22}$

In a qualitative study in which the experience of RP was considered to be a transition, ie, the interruption of a patient's current reality requiring the construction of a new reality, men mentioned the role of nurse educators in this transition process, referring to the influence of information provision and preoperative preparation, including education in the use of adaptive strategies to cope with problems in the postoperative period. ${ }^{13}$

The information offered by nurses in the preoperative period is usually related to routine surgical procedures, such as skin preparation, fasting, time of surgery, and use of bladder catheters. ${ }^{22}$ However, some studies reported weaknesses in the nurse-patient communication process before prostatectomy that interfered in interpersonal relationships based on empathy, respect, and trust. ${ }^{22,23}$ Furthermore, these studies revealed a lack of concern about the psychosocial and emotional aspects of prostate surgery, such as patients' expectations about sexuality and the possibilities of UI and infertility. ${ }^{22,23}$

The quality of information increases patients' involvement in treatment. Although most patients can initially adapt to the side effects of RP, particularly UI, nurses must understand that this adaptation does not mean that symptoms are unimportant or easily managed. The treatment of post-prostatectomy UI should begin at the time of $\mathrm{PCa}$ diagnosis and surgical planning, when this problem can be self-managed. ${ }^{17}$ In other words, instruction in pelvic muscle exercises during the preoperative and postoperative periods can help patients control UI. ${ }^{24}$

Psychosocial issues related to radiotherapy include patients' concerns about sexuality and radioactivity. Patient education should be focused on the specific treatment modality and its curative or palliative intent. Information about the experience of radiotherapy must be provided objectively and include descriptions of the temporal aspects of procedures, the treatment environment, and common physical sensations. One study found that comparison of radiotherapy with an X-ray exam was helpful. ${ }^{6}$

\section{Nursing care in the posttreatment period}

Many studies have examined patient care in the posttreatment period, mainly following prostatectomy. Nurses' assistance is seen as fundamental to minimize patients' negative experiences. ${ }^{13}$ Post-prostatectomy nursing care includes general activities, such as urinary catheter care, infection prevention, and the provision of appropriate nutrition and hydration; postoperative activities, such as hygiene and surgical wound care; monitoring of medication administration; and education in the signs and symptoms of postoperative complications, pelvic-floor muscle exercises, and pain control. ${ }^{12,25}$

The provision of information about the importance of water intake and catheter care after surgery is indispensable to prevent urinary tract infection and essential in association with UI interventions, as these problems cause physical and emotional distress that may delay recovery. ${ }^{24}$ Nursing care must also address less common problems, such as hyponatremia: recognition of the signs, symptoms, and physiopathology of this condition, and the necessity of treatment (unlike chronic hyponatremia, postoperative hyponatremia must be treated) and means of prevention (eg, replacement of normal saline irrigation as soon as possible, as excessive irrigation after prostatectomy can cause hyponatremia) are necessary. ${ }^{5}$

In the context of hospital discharge, effective interaction between nurses and patients can establish contacts facilitating the detection of problems and implementation of appropriate educational interventions. This care can facilitate the resolution of patients' problems. ${ }^{24}$ Interventions combining written guidance with oral information are important for the development of home self-care skills. ${ }^{25}$ At the time of discharge, educational interventions focusing on pain control and relief, use of prescription drugs, and urinary catheter care to prevent obstruction are indispensable, as pain and the large number of prescriptions can lead to medication errors at home. ${ }^{24}$ From 3 to 5 days after discharge, major concerns were bladder spasms, scrotal swelling, constipation, pain, and activity restrictions. ${ }^{26}$ Patients reported that they felt relatively comfortable when they understood their postdischarge self-care responsibilities and possessed knowledge about their medications. ${ }^{26}$

The studies included in this analysis highlighted the importance of nursing guidelines providing answers to questions from patients and partners/caregivers and information about postoperative care. In addition, nurses' availability to listen to patients and identify and discuss psychological and emotional needs were also found to be important. ${ }^{5}$

In the late postoperative period, UI and related emotional responses, such as fear and anxiety, require special attention. ${ }^{21,25}$ Nurses must understand the diversity and individuality of UI and erectile dysfunction manifestations, as well as all aspects involved and different ways of viewing and accepting these conditions, with consideration of their strong impacts on quality of life. ${ }^{5,25}$ Nursing interventions, 
Table 2 Characteristics of articles included in the review

\begin{tabular}{llll}
\hline $\begin{array}{l}\text { Article, year, } \\
\text { country }\end{array}$ & Objective & Method and sample & Results $^{\mathbf{a}}$ \\
\hline $\begin{array}{lll}\text { Costa et al, }{ }^{22} 2013, & \text { To investigate therapeutic } & \text { I } \\
\text { Brazil } & \text { communication between nurses and } \\
& \text { patients in the pre-prostatectomy } & \text { Brazilian nurses. }\end{array}$ &
\end{tabular}
period.

\begin{tabular}{ll}
\hline Santos et al, ${ }^{5} 2012$, & To synthesize the knowledge \\
Brazil & produced in articles regarding nursing \\
& care provided to patients after \\
& prostatectomy.
\end{tabular}

Krumwiede and To investigate the lived experience Krumwiede, ${ }^{16} 2012$, of prostate cancer from a patient USA perspective.

\begin{tabular}{ll}
\hline Carvalho and & To understand the process of \\
Cristão, ${ }^{13} 2012$, & transition for men with prostate \\
Portugal & $\begin{array}{l}\text { cancer undergoing radical } \\
\text { prostatectomy. }\end{array}$
\end{tabular}

Lynch, ${ }^{20}$ 2012, UK To explain how those who are at advanced stages in their careers can further develop skills in the voluntary sector as specialist nurses.
Integrative review of 19 articles.

$\begin{array}{ll}\text { Qualitative descriptive study, } & \text { Help patients understand the full } \\ \text { hermeneutic phenomenological } & \text { implications of the disease process and } \\ \text { method; ten men with prostate } & \text { treatment options. }\end{array}$
cancer.

Qualitative descriptive exploratory study, content analysis; semistructured interviews with 18 participants. implications of the disease process and

\section{Quantitative descriptive study;} helpline data captured between 2010 and 2011 ; specialist nurses' experiences.

\begin{tabular}{ll}
\hline Carter et al, ${ }^{14} 201 \mathrm{I}$, & To better understand the priority \\
Canada & $\begin{array}{l}\text { supportive care needs of men with } \\
\text { advanced prostate cancer. }\end{array}$
\end{tabular}

Harju et al, ${ }^{27} 201 \mathrm{I}, \quad$ To describe perceived family health Finland in persons with prostate cancer and their family members.
Qualitative descriptive study; focus groups and interviews with 12 men with hormone-sensitive and 17 men with hormone-refractory prostate cancer.
As specialists, nurses can maintain competence and reflection in practice, helping patients and families come to terms with a diagnosis of prostate cancer and the required management of the disease, considering treatment decisions tailored to patients' lifestyles. Patients require support to meet their stage-specific information needs and to address concerns about the diagnosis and feelings about treatment decisions.
Cross-sectional study, data collected using the modified Family Functioning, Health and Social Support scale; 76 persons with prostate cancer and 7 I family members.

\begin{tabular}{lll}
\hline Inman et al, ${ }^{26} 201 \mathrm{I}$, & To determine whether patients & Randomized controlled trial, \\
USA & receiving additional follow-up & telephone education 3-5 days after \\
& education by telephone after radical & hospital discharge; 60 patients after \\
& prostatectomy have increased & radical prostatectomy. \\
& understanding compared with patients
\end{tabular}
understanding compared with patients receiving usual care (no follow-up call), and whether the telephone follow-up educational protocol increased overall patient satisfaction. Mata et al, ${ }^{24} 201 \mathrm{I}, \quad$ To validate the content of nursing Brazil interventions in preparing patients who have undergone prostatectomy for discharge. Methodological study validating 93 interventions; 38 experts. 


\section{Category 2}

Nurse-patient communication before prostatectomy facilitates interpersonal relationships, allowing expression of feelings and information exchange. Most information offered in the preoperative period is related to routine surgical procedures.

The studies addressed patient care in the postoperative period involving nurses' availability to listen to patients, allowing identification and discussion of their need for emotional support.
Guide and clarify patients' and partners'/ caregivers' doubts about postoperative care by providing information about care and pain relief, possibility of erectile dysfunction and urinary incontinence, and possible treatments. Offer support to patients and families related to the impacts of cancer diagnosis and treatment; include family members in aspects of health care.
Educator nurses' roles begin in the preoperative period with adaptive strategies to cope with possible postsurgical morbidity.
Nurses can help to establish communication able to assist patients in finding ways to accept their new status; this function is a fundamental aspect of developing confidence, encouraging the health care and more positive relationships, and minimizing patients' negative life experiences.
Provision of specialized nurse intervention and individualized care by telephone to patients and family members.
Implementation of educational intervention strategies during hospitalization period promotes effective interaction and allows detection and resolution of postoperative problems.
Hear, support, and give opportunities to patients and families to participate in care planning and treatment decisions. Pay attention to the feelings and needs of family members.

Educational calls provide meaningful information during the period when patients experience management of their own care. Individual followup care by telephone to provide postoperative information effectively assists patients in recalling information.

84 interventions were validated and shown to be relevant for the patients' preparation for discharge in the Brazilian context. Provision of information to patients and families about the ability to call with questions about pain relief or urinary urgency or frequency are not yet part of Brazilian nurses' reality. 
Table 2 (Continued)

\begin{tabular}{llll}
\hline $\begin{array}{l}\text { Article, year, } \\
\text { country }\end{array}$ & Objective & Method and sample & Results \\
\cline { 2 - 3 } & Category I & \\
\hline
\end{tabular}

Mata and To identify the knowledge produced Integrative review of 25 articles.

Napoleão, ${ }^{25} \quad$ by nursing interventions related

2010, Brazil to preparing patients for hospital

discharge after prostatectomy.

\begin{tabular}{|c|c|c|c|}
\hline $\begin{array}{l}\text { Tarrant et al, }^{18} \\
2008, \text { UK }\end{array}$ & $\begin{array}{l}\text { To explore the role and value of } \\
\text { specialist nurses in prostate cancer } \\
\text { care via a survey and patient } \\
\text { interviews. }\end{array}$ & $\begin{array}{l}\text { Quantitative questionnaire-based } \\
\text { survey of } 289 \text { patients; qualitative } \\
\text { analysis of semi-structured interviews } \\
\text { with } 35 \text { men and ten wives. }\end{array}$ & $\begin{array}{l}\text { Provide information about } \\
\text { diagnosis and treatment in clearly } \\
\text { understandable terms and to } \\
\text { facilitate the care process. }\end{array}$ \\
\hline $\begin{array}{l}\text { McCorkle et al, } \\
2007, \text { USA }\end{array}$ & $\begin{array}{l}\text { To determine the effects of a } \\
\text { standardized nursing intervention } \\
\text { on men's and their spouses' levels of } \\
\text { depressive symptoms, sexual function, } \\
\text { and marital interaction following } \\
\text { radical prostatectomy over time. }\end{array}$ & $\begin{array}{l}\text { Secondary analysis of data from } \\
107 \text { patients and spouses; outcome } \\
\text { variables measured at baseline and } \\
\text { I, } 3 \text {, and } 6 \text { months following radical } \\
\text { prostatectomy. }\end{array}$ & \\
\hline $\begin{array}{l}\text { Couper et al, }{ }^{28} \\
2006, \text { Australia }\end{array}$ & $\begin{array}{l}\text { To appraise published research on } \\
\text { the psychosocial effects on women } \\
\text { living with men diagnosed with } \\
\text { prostate cancer at whatever point } \\
\text { in their "journey". }\end{array}$ & $\begin{array}{l}\text { Review of } 44 \text { articles published } \\
\text { between } 1994 \text { and } 2005 .\end{array}$ & \\
\hline $\begin{array}{l}\text { Rayford, }{ }^{19} 2006, \\
\text { USA }\end{array}$ & $\begin{array}{l}\text { To discuss how low socioeconomic } \\
\text { status and educational level can } \\
\text { adversely influence therapeutic } \\
\text { decision making. }\end{array}$ & Literature review. & $\begin{array}{l}\text { Implementation of educational } \\
\text { programs specifically for patients } \\
\text { and families of low socioeconomic } \\
\text { level improves communication and } \\
\text { understanding of prostate cancer and } \\
\text { results in higher levels of acceptance of } \\
\text { advocated treatments. }\end{array}$ \\
\hline
\end{tabular}

\begin{tabular}{|c|c|c|c|}
\hline $\begin{array}{l}\text { Burt et al, }{ }^{21} 2005 \\
\text { Canada }\end{array}$ & $\begin{array}{l}\text { To explore men's experiences after } \\
\text { radical prostatectomy and whether } \\
\text { they perceived that preoperative } \\
\text { education adequately prepared them } \\
\text { for postoperative recovery. }\end{array}$ & $\begin{array}{l}\text { Qualitative descriptive study; semi- } \\
\text { structured telephone interviews with } \\
\text { I7 participants. }\end{array}$ & \\
\hline $\begin{array}{l}\text { Calabrese, }{ }^{15} 2004, \\
\text { USA }\end{array}$ & $\begin{array}{l}\text { To discuss screening, diagnosis, and } \\
\text { treatment modalities for prostate } \\
\text { cancer in men aged }>65 \text { years. }\end{array}$ & Literature review. & $\begin{array}{l}\text { Education about comorbidities that } \\
\text { may influence available treatment } \\
\text { options helps patients make the best } \\
\text { cancer treatment decisions. }\end{array}$ \\
\hline $\begin{array}{l}\text { McGlynn et al, }{ }^{17} \\
\text { 2004, UK }\end{array}$ & $\begin{array}{l}\text { To improve the preoperative process } \\
\text { and education for men planning to } \\
\text { undergo surgery for genitourinary } \\
\text { cancers. }\end{array}$ & $\begin{array}{l}\text { Follow-up telephone calls and } \\
\text { administration of International Prostate } \\
\text { Symptom Score questionnaire to a } \\
\text { convenience sample of } 106 \text { patients } \\
\text { after radical prostatectomy. }\end{array}$ & $\begin{array}{l}\text { Understand and agree to possible } \\
\text { compromises in treatment with regard } \\
\text { to the benefits and potential side effects } \\
\text { of surgery; help patients adapt to the } \\
\text { side effects of radical prostatectomy, } \\
\text { particularly incontinence. }\end{array}$ \\
\hline $\begin{array}{l}\text { Iwamoto and } \\
\text { Maher, }{ }^{6} 200 \text { I, USA }\end{array}$ & $\begin{array}{l}\text { To review advances in radiation } \\
\text { therapy for prostate cancer and the } \\
\text { nursing care of patients with prostate } \\
\text { cancer. }\end{array}$ & $\begin{array}{l}\text { Review of peer-reviewed journal } \\
\text { articles. }\end{array}$ & $\begin{array}{l}\text { Managing symptoms associated with } \\
\text { the disease and treatment; educating } \\
\text { patients and family members about } \\
\text { radiotherapy; providing patient support } \\
\text { throughout the course of the illness. }\end{array}$ \\
\hline
\end{tabular}




\section{Category 2}

\section{Category 3}

The following nursing interventions were identified: general interventions; urinary catheter care; prevention of infection; nutrition and hydration care; return to activities; hygiene care; medication administration care; guidance on expected signs and symptoms postoperatively; guidance on signs and symptoms of complications and conduits; guidelines for pelvic muscle exercises and pain control.

\section{Category 4}

Provide written information about postoperative care to minimize anxiety and promote greater safety for patients and their families.

Levels of affected couples' depressive symptoms should be assessed and monitored; patients and spouses need to be included in discussions about the effects of cancer and its treatment so that both feel more prepared to manage them.

The literature suggests that partners report more distress than patients, but believe that patients are more distressed; patients' focus of concern on their sexual function is not shared to an equal degree by their partners. Implementing educational strategies designed to improve posttreatment monitoring of patients, advising on management of posttreatment complications, and providing psychosocial support for patients and their families.

A good source of information helped patients make the decision to have surgery. Nurses need to be prepared educationally and psychologically to observe nonverbal cues and address questions and concerns of significance.
Telephone follow-up helps foster adjustment after surgery and relieves anxiety caused by side effects of surgery and unanswered questions.

Personalized education increased the rate of postoperative return of continence, patients' satisfaction with surgery, and quality of life.

To help family members through support, encouragement, and active listening, especially when prostate cancer is a terminal diagnosis.

Focus on patient education varies depending on the modality and overall goal of

radiotherapy (ie, curative or palliative). 
Table 2 (Continued)

\begin{tabular}{|c|c|c|c|}
\hline \multirow{2}{*}{$\begin{array}{l}\text { Article, year, } \\
\text { country }\end{array}$} & \multirow[t]{2}{*}{ Objective } & \multirow[t]{2}{*}{ Method and sample } & Results $^{\mathbf{a}}$ \\
\hline & & & Category I \\
\hline $\begin{array}{l}\text { Robinson et al, }{ }^{23} \\
\text { 1999, USA }\end{array}$ & $\begin{array}{l}\text { To describe postsurgical nursing } \\
\text { interventions for men with prostate } \\
\text { cancer. }\end{array}$ & $\begin{array}{l}\text { Secondary descriptive analysis of data } \\
\text { collected from } 32 \text { randomly selected } \\
\text { patients with prostate cancer using the } \\
\text { Nursing Intervention Lexicon and } \\
\text { Taxonomy. }\end{array}$ & \\
\hline $\begin{array}{l}\text { Jakobsson et al, }{ }^{12} \\
\text { 1997, Sweden }\end{array}$ & $\begin{array}{l}\text { To describe nursing care needs } \\
\text { perceived by patients during the } \\
\text { inpatient period, and men's opinions } \\
\text { of their quality of life and sense of } \\
\text { coherence. }\end{array}$ & $\begin{array}{l}\text { Phenomenological-hermeneutic } \\
\text { approach; convenience sample of } \\
\text { eleven men with prostate cancer; } \\
\text { semi-structured EORTC QLQ-C30.' }\end{array}$ & $\begin{array}{l}\text { Nurses must be aware of and sensitive } \\
\text { to undertones in statements and } \\
\text { actively seek to understand patients' } \\
\text { needs. }\end{array}$ \\
\hline
\end{tabular}

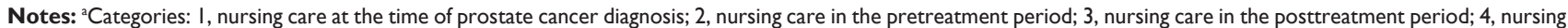
care for families and partners of men with prostate cancer; ba questionnaire developed to assess quality of life in patients with cancer.

Abbreviation: EORTC QLQ-C30, European Organization for Research and Treatment of Cancer Quality of Life Questionnaire.

such as the use of diapers or pads and pelvic-floor muscle exercises, can minimize UI and related emotional issues. After the return of urinary continence, patients focus on erectile function and wish to know when their sex lives will return to normal. ${ }^{25}$

The side effects of external-beam radiotherapy are site specific, as only tissues and structures within the radiation field are affected. Acute side effects include diarrhea, proctitis, cystitis, fatigue, and mild skin irritation, primarily in the gluteal fold. Late effects include chronic enteritis, bladder contraction, and erectile dysfunction. Brachytherapy requires a short hospital stay; patients usually return home on the same day, frequently with an indwelling urinary catheter. The postoperative complications of brachytherapy include pain, cystitis symptoms, hematuria, infection, enteritis, and fatigue. Cystitis symptoms can be severe and may require an indwelling catheter and/or intermittent self-catheterization. ${ }^{6}$ One review presented several nursing interventions to manage complications following external-beam radiotherapy and brachytherapy for $\mathrm{PCa}$, such as screening for bladder infection or assessing energy level to investigate the causes of cystitis and fatigue, respectively. ${ }^{6}$ Some authors have also recommended the provision of nursing assistance through a telephone helpline. ${ }^{20,26}$ Patients reported that individual reinforcement of education by telephone was helpful and reduced the need to utilize other resources to seek nursing intervention. ${ }^{26}$ The provision of emotional support through helplines is an increasingly common theme; in this manner, nurses can help callers who feel anxious during hospital appointments. Telephone interventions help patients who may not otherwise obtain psychosocial care due to factors such as isolation, physical limitations, or discomfort with more intimate approaches. ${ }^{20}$

\section{Nursing care for partners and family members of men with PCa}

Nurses can play important roles in implementing educational strategies designed to improve knowledge about $\mathrm{PCa}$ and its treatment, posttreatment monitoring, offering advice on the management of complications, and providing psychosocial support for patients and their families. ${ }^{19}$ Nursing care should be based on an individualized understanding of the situations of patients with $\mathrm{PCa}$ and their families. In practice, nurses should pay attention to the feelings and needs of family members of men undergoing PCa treatment; a patient's illness may affect the health of his entire family. ${ }^{27}$

Nurses must be prepared to support patients with $\mathrm{PCa}$ and their families throughout the life experience of this disease, be aware of the impacts of PCa diagnosis and treatment on patients' families, include family members in all aspects of health care, and emphasize the importance of support systems in coping with the uncertainties of the disease. ${ }^{16}$ When PCa results in a terminal diagnosis, nurses must help patients and their families obtain the best end-of-life care. ${ }^{15}$

Men with PCa and their family members need to be heard, supported, and given opportunities to participate in care planning and decision making through individualized focused services. ${ }^{27}$ Nurses must assess and continually monitor levels of depressive symptoms, sexual function distress, marital interaction distress, and any other indication for psychosocial interventions in men who have undergone RP and their partners. ${ }^{28,29}$ Patients reported significantly more distress pertaining to sexual function than did their partners, and partners reported significantly more marital interaction distress than did patients. ${ }^{29}$ Partners tend to reassure patients 


\section{Category 2}

\section{Category 3}

Category 4

Two major categories of intervention: patient

education and psychological. Data on the most

prevalent interventions enable better preparation

of nurse generalists to anticipate care needs

of men undergoing prostate surgery.

Provide solutions to physical problems together

with staff support, including information, and act

to increase confidence in staff and staff availability.

who experience impotence and do not address their own sexual needs. ${ }^{28}$

Conversely, UI may have a greater adverse psychological effect on partners than on patients, ${ }^{28}$ and levels of depressive symptoms are significantly higher in partners than in patients. ${ }^{29}$ Partners' perceptions of support enhance their relationship satisfaction and enable them to shoulder the emotional burdens related to living with the effects of patients' PCa. Psychoeducational interventions may help partners develop a more positive approach. ${ }^{28}$

Several studies highlighted the recommendations for emotional support, education, and care for patients, partners, and family members in guidelines for the treatment of erectile dysfunction. ${ }^{5,8,12,30}$ These actions are essential in the therapeutic process, involving these parties more actively in treatment. ${ }^{5}$

Examinations of performance-based evidence regarding prostatectomy have also sought to identify the most effective forms of guidance for patients and their families in self-care and the best forms of action toward UI and sexual dysfunction, as well as the most frequent nursing diagnoses focusing on these sequelae in discharge planning. ${ }^{25}$ Expert nurses must assess the need to provide family members with care knowledge by telephone and specialized, directed, and individualized interventions. ${ }^{20}$

\section{Discussion}

Several authors of studies included in this analysis recommended that care for patients with PCa and their families begin at the moment of diagnosis and extend into the post-discharge period..$^{13,17}$ The provision of assistance after discharge is very important because some problems appear late. Nursing assistance provided via telephone helplines is very useful, but new strategies and models of care should be tested and implemented.

The ProsCan for Couples project, for example, evaluated the efficacy of two couples-based sexuality interventions delivered by telephone for men with localized PCa who had undergone RP: peer support (volunteer PCa survivors with support group experience) and nurse counseling. ${ }^{30}$ The feasibility of delivering peer support was evaluated with ten volunteers, and this model appears to be promising for the support of couples facing $\mathrm{PCa} .{ }^{30}$

Health assistance for PCa survivors needs to be improved. Frew and Dashfield ${ }^{31}$ stated that the current model of care is based on a unique model for all patients that focuses on the disease, rather than the person. They affirmed that "nurses have a pivotal role in supporting the shift from this traditional model to one based on helping patients to help themselves." ${ }^{\text {"31 }}$ This new model of care requires the redesigning of care pathways. These authors proposed stratification of the process such that patients agree in partnership with the clinical team on a care pathway. For complex patients a professional clinical team-led model is recommend; for those unable to self-manage, a supportive patient and professional model is necessary; a patient self-managed model is possible if the patients have been equipped to manage their own care, with monitoring of ongoing tests and direct access in case of problems' occurrence. ${ }^{31}$

As observed in this review, the inclusion of partners and family members in nursing care for PCa survivors is also recommended because many of these family members become physically and emotionally ill in the process of caring for patients after PCa treatment. ${ }^{8}$ Furthermore, the articles analyzed showed that male sexual dysfunction affects men and women differently, necessitating the individualization of 
care to meet each partner's needs. Psychosocial interventions that facilitate healthy spousal communication and address the sexual rehabilitation needs of patients and their partners after PCa treatment are necessary. These discussions may help alleviate the negative impacts of sexual problems on couples' marital adjustment, although some individuals may be reluctant to engage in constructive cancer-related discussions about sexual problems. ${ }^{28}$ Couples lose control upon the diagnosis of cancer and in the subsequent period of surgery, and their ability to regain a sense of mastery, for example by gaining command over UI and impotence, is critical for successful recovery. ${ }^{32}$ During this process, the supportive presence of the partner and work as a couple to establish a routine and strengthen intimacy are essential. ${ }^{32}$

Although our search identified no randomized clinical trial or integrative/systematic review evaluating the efficacy or effectiveness of specific nursing interventions, many authors of the included studies argued that individualized approaches throughout the process, from diagnosis to recovery, which promote self-care and involve partners and families, are most appropriate and may lead to better results. ${ }^{13,17,31}$

In general, the articles did not clearly indicate whether the interventions described involved only clinical nurse specialists. However, considering that patients with $\mathrm{PCa}$ require specialized care by a nurse with expert knowledge, complex decision-making skills, and specific clinical competencies, as demonstrated by this literature review, these articles can be considered to describe the role of clinical nurse specialists. In addition to variation among countries in the definition of this position, a study conducted in the UK showed great variation in the qualifications and experience of PCa clinical nurse specialists and in the services they provided, ranging from generic support and information provision throughout all stages of treatment and care to services to meet specific care needs, such as lower urinary tract symptoms and erectile dysfunction. ${ }^{33}$ In addition, the variability in services has implications for access to, and equity of, specialist nursing services, mainly due to the rapidly growing caseloads of nurses caring for patients with $\mathrm{PCa}$. This variability can compromise efforts to define clinical nurse specialists' contributions to care, others' expectations of the specialist nursing role, and the evaluation of their outcomes. ${ }^{33}$

Another important issue is whether clinical nurse specialists in urology or oncology have more skills and knowledge related to caring for men with PCa. Those in urology have skills and knowledge related to several conditions that patients with PCa may experience, but may not have advanced knowledge and skills in cancer-specific issues. Thus, we agree with the UK Prostate Cancer Charity ${ }^{7}$ that access to a uro-oncology clinical nurse specialist may be most beneficial for men with $\mathrm{PCa}$, but the qualitative and quantitative provision of these professionals to health services is a major challenge. ${ }^{7}$

In countries such as the UK, the roles and responsibilities of nurses have recently been extended, and nurse-led services have been created. ${ }^{7}$ In such services, nurses are given significant responsibility for the care of patients that is usually the responsibility of doctors in a particular setting (eg, fine-needle aspiration of breast lesions). ${ }^{34} \mathrm{~A}$ review documented the success of nurseled clinics and their positive impacts on patient satisfaction. ${ }^{34}$ This new model of care may change the nursing practice in the future and greatly impact how health care is provided.

\section{Conclusion}

The role of clinical nurse specialists in caring for men with PCa is broad and essential, but its definition must be standardized among countries and regions. In addition, well-designed clinical studies are needed to evaluate interventions and new strategies for care.

\section{Disclosure}

The authors report no conflicts of interest in this work.

\section{References}

1. Ferlay J, Soerjomataram I, Ervik M, et al. F.GLOBOCAN 2012 v1.0, Cancer Incidence and Mortality Worldwide: IARC CancerBase No 11 [webpage on the Internet]. Lyon, France: International Agency for Research on Cancer; 2013. Available from: http://globocan.iarc.fr/Pages/ fact_sheets_cancer.aspx. Accessed December 13, 2013.

2. Heidenreich A, Bastian PJ, Bellmunt J, et al. European Association of Urology. Guidelines on Prostate Cancer. 2013. European Association of Urology. Available from: http://www.uroweb.org/gls/ pdf/09_Prostate_Cancer_LR.pdf. Accessed: September 28, 2013.

3. de Moraes Lopes MH, Higa R, Cordeiro SN, Rodrigues Estapê NA, Levi D'ancona CA, Turato ER. Life experiences of Brazilian men with urinary incontinence and erectile dysfunction following radical prostatectomy. $J$ Wound Ostomy Continence Nurs. 2011;38(6):1-5.

4. Srougi M. Surgical complications of retropubic radical prostatectomy: personal experience with 974 operations. J Bras Urol. 1999;25(1):42-52.

5. Santos DRF, Silva FBL, Saldanha EA, Lira ALBC, Vitor AF. Cuidados de enfermagem ao paciente em pós-operatório de prostatectomia: revisão integrativa. [Nursing care of postoperative prostatectomy patients: an integrative review.] Revista Eletrônica de Enfermagem [serial on the Internet]. 2012;14(3):690-701. Available from: from: http://www.fen. ufg.br/fen_revista/v14/n3/pdf/v14n3a27.pdf. Accessed September 27, 2013. Portuguese.

6. Iwamoto RR, Maher KE. Radiation therapy for prostate cancer. Semin Oncol Nurs. 2001;17(2):90-100.

7. Access to Clinical Nurse Specialists for Men with Prostate Cancer: The Prostate Cancer Charity Policy Position August 2009. London: The Prostate Cancer Charity. Available from: http://prostatecanceruk.org/ media/36697/accesstocns.pdf. Accessed January 7, 2014.

8. Bicalho MB, Lopes MH. Impacto da incontinência urinária na vida de esposas de homens com incontinência: revisão integrativa [The impact of urinary incontinence of the lives of wives of men with incontinence: an integrative review]. Rev Esc Enferm USP. 2012;46(4):1009-1014. Portuguese. 
9. Galbraith ME, Pedro LW, Jaffe AR, Allen TL. Describing health-related outcomes for couples experiencing prostate cancer: differences and similarities. Oncol Nurs Forum. 2008;35(5):794-801.

10. Nursing Matters: Nurse Practitioner/Advanced Practice Nurse: Definition and Characteristics. Geneva: International Council of Nurses; 2009. Available from: http://acnp.org.au/sites/default/files/33/ definition_of_apn-np.pdf. Accessed January 7, 2014.

11. Rother ET. Systematic literature review X narrative review. Acta paulista de enfermagem. 2007;20(2):v-vi. Available from: http://www.scielo.br/ pdf/ape/v20n2/en_a01v20n2.pdf. Accessed March 24, 2014.

12. Jakobsson L, Hallberg IR, Lovén L. Met and unmet nursing care needs in men with prostate cancer. An explorative study. Part II. Eur J Cancer Care (Engl). 1997;6:117-123.

13. Carvalho JMS, Cristão ASM. The value of nursing care: nursing consultations for men undergoing radical prostatectomy. Revista de Enfermagem Referência. 2012;3(7):103-112.

14. Carter N, Bryant-Lukosius D, DiCenso A, Blythe J, Neville AJ. The supportive care needs of men with advanced prostate cancer. Oncol Nurs Forum. 2011;38(2):189-198.

15. Calabrese DA. Prostate cancer in older men. Urol Nurs. 2004;24(4): 258-269.

16. Krumwiede KA, Krumwiede N. The lived experience of men diagnosed with prostate cancer. Oncol Nurs Forum. 2012;39(5):E443-E450.

17. McGlynn B, Al-Saffar N, Begg H, et al. Management of urinary incontinence following radical prostatectomy. Urol Nurs. 2004;24(6): 475-482, 515 .

18. Tarrant C, Sinfield P, Agarwal S, Baker R. Is seeing a specialist nurse associated with positive experiences of care? The role and value of specialist nurses in prostate cancer care. BMC Health Serv Res. 2008;8:65.

19. Rayford W. Managing the low-socioeconomic-status prostate cancer patient. J Natl Med Assoc. 2006;98(4):521-530.

20. Lynch T. Telephone helpline supports patients with prostate cancer. Cancer Nursing Practice. 2012;11(3):30-34.

21. Burt J, Caelli K, Moore K, Anderson M. Radical prostatectomy: men's experiences and postoperative needs. J Clin Nurs. 2005;14(7): 883-890.

22. Costa TF da, Costa KNFM, Martins KP, Oliveira DST, Lima JTS, Arruda AJCG. Comunicação terapêutica entre enfermeiros e pacientes em pré-operatório de prostatectomia. [Therapeutic communication between nurses and patients of preoperative prostatectomy.] Revista de Enfermagem UFPE On Line. 2013;7(4):1107-1112. Portuguese.
23. Robinson L, Hughes LC, Adler DC, Strumpf N, Grobe SJ, McCorkle R. Describing the work of nursing: the case of postsurgical nursing interventions for men with prostate cancer. Res Nurs Health. 1999;22(4): 321-328.

24. Mata LRF da, Carvalho EC de, Napoleão AA Validação por peritos de intervenções de enfermagem para a alta de pacientes submetidos à prostatectomia. [Validating nursing interventions by specialists concerning discharging patients who have undergone prostatectomies.] Texto \& contexto enfermagem. 2011;20(Esp): 36-44. Portuguese.

25. Mata RLF, Napoleão AA. Nursing interventions for patients discharged from prostatectomy: an integrative review. Acta paulista de enfermagem. 2010;23(4):574-579.

26. Inman DM, Maxson PM, Johnson KM, Myers RP, Holland DE. The impact of follow-up educational telephone calls on patients after radical prostatectomy: finding value in low-margin activities. Urol Nurs. 2011;31(2):83-91

27. Harju E, Rantanen A, Tarkka MT, Astedt-Kurki P. Perceived family health in persons with prostate cancer and their family members. $J$ Clin Nurs. 2011;21(3-4):544-554.

28. Couper J, Bloch S, Love A, Macvean M, Duchesne GM, Kissane D. Psychosocial adjustment of female partners of men with prostate cancer: a review of the literature. Psychooncology. 2006;15(11):937-953.

29. McCorkle R, Siefert ML, Dowd MF, Robinson JP, Pickett M. Effects of advanced practice nursing on patient and spouse depressive symptoms, sexual function, and marital interaction after radical prostatectomy. Urol Nurs. 2007;27(1):65-77.

30. Chambers SK, Schover L, Halford K, et al. ProsCan for Couples: randomised controlled trial of a couples-based sexuality intervention for men with localized prostate cancer who receive radical prostatectomy. BMC Cancer. 2008;8:226.

31. Frew G, Dashfield E. Testing care pathways for prostate cancer survivors. Nurs Times. 2012;108(13):30-31.

32. Maliski SL, Heilemann MV, McCorkle R. Mastery of postprostatectomy incontinence and impotence: his, work, her work, our work. Oncol Nurs Forum. 2001;28(6):985-992.

33. Ream E, Wilson-Barnett J, Faithfull S, Fincham L, Khoo V, Richardson A. Working patterns and perceived contribution of prostate cancer clinical nurse specialists: a mixed method investigation. Int J Nurs Stud. 2009;46:1345-1354

34. Corner J. The role of nurse-led care in cancer management. Lancet Oncol. 2003;4:631-636.
Nursing: Research and Reviews

\section{Publish your work in this journal}

Nursing: Research and Reviews is an international, peer-reviewed, open access journal publishing original research, reports, reviews and commentaries on all aspects of nursing and patient care. These include patient education and counselling, ethics, management and organizational issues, diagnostics and prescribing, economics and

\section{Dovepress}

resource management, health outcomes, and improving patient safety in all settings. The manuscript management system is completely online and includes a very quick and fair peer-review system. Visit http://www.dovepress.com/testimonials.php to read real quotes from published authors. 